\title{
Centenary of Haematologica
}

\section{Carlo L. Balduini}

Ferrata-Storti Foundation, Pavia, Italy

E-mail: CARLOL.BALDUINI, - carlo.balduini@unipv.it

doi:10.3324/haematol.2019.244939

1 he first issue of Haematologica was printed in January 1920. Today, therefore, the journal is 100 years old and represents the oldest hematology journal. The cover of this issue aims to synthesize the 100years history of Haematologica (Figure 1).

As illustrated by Paolo Mazzarello in the Centenary Review in this issue, Haematologica has played an important role in the dissemination of knowledge on the subject of hematology and has hosted articles that have contributed to writing the history of this branch of medicine.

This was possible thanks to the work of the many generations of editors who, after the founders Adolfo Ferrata and Carlo Moreschi, succeeded one another in the direction of the journal and were able to keep it alive even in dark periods of our recent history characterized by economic crises and a war that devastated the whole world.

The journal, despite its one hundred years, is in excellent health, as demonstrated by the over two thousand papers submitted each year, by the 10 million visits that its website receives and by more than 1 million articles downloaded annually. Moreover, the articles published in Haematologica are among the most cited in the field of hematology.

The Ferrata Storti-Foundation, which owns and publishes Haematologica, is a non-profit organization, and this allows us to keep the costs for the authors low and everything published is available online for free.

The way in which the Foundation intends to celebrate the centenary is in line with this idea of a scientific journal: from January of this year the Haematologica website hosts a new, online Hematology Atlas (Figure 2) that is available for free to all readers. Being involved in this initiative as an editor, I am not allowed to say that it is a good atlas, but I can only report that it has nearly 300 pages and contains 800 images with detailed captions distributed in 35 chapters, each with a brief introduction explaining the diagnostic utility of evaluating peripheral blood and marrow smears. Rosangela Inverizzi, the lead author of the Atlas, and the editor have made every effort to ensure that the images appearing on the screen faithfully reproduce what is seen under the microscope. A printed version is available for those who want to have the atlas next to the microscope.

I believe that the Haematologica centenary is an appropriate occasion to thank all those who have contributed to the success of the journal: authors, editors, associated editors, and reviewers, as well as all members of the editorial staff. Thanks above all to Haematologica readers, who have contributed decisively to its achievements.

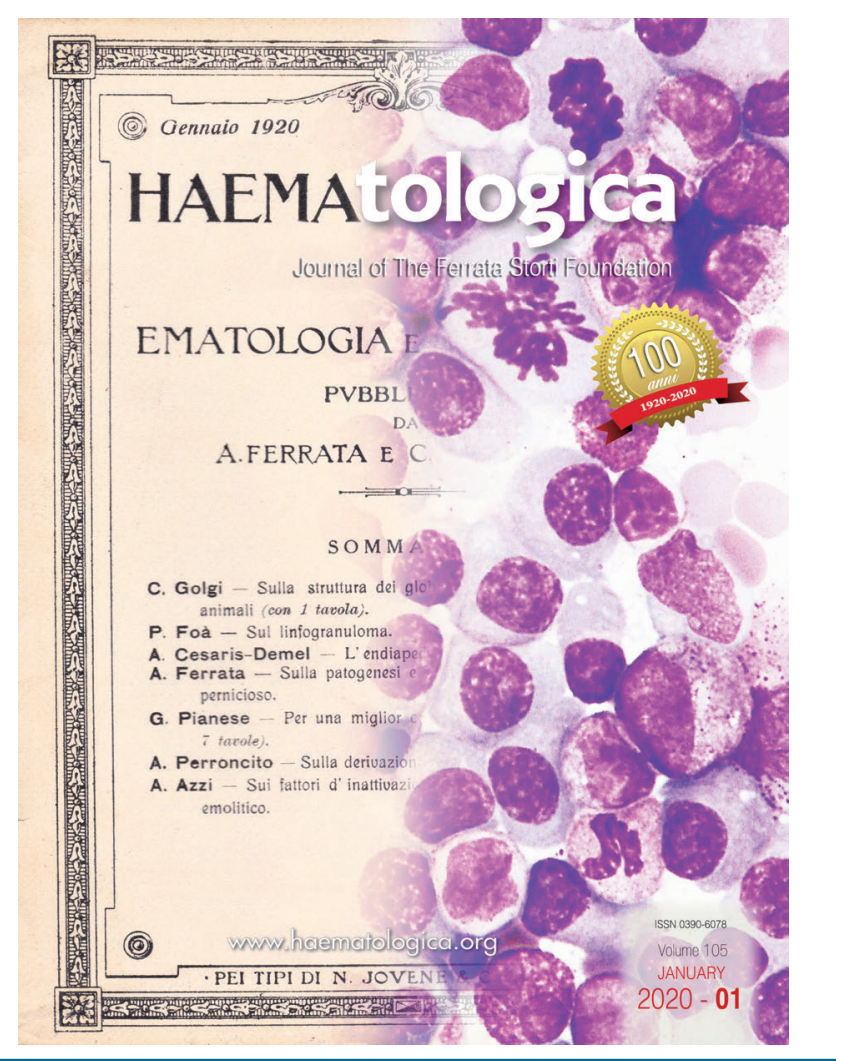

Figure 1. Cover of the Centenary issue.

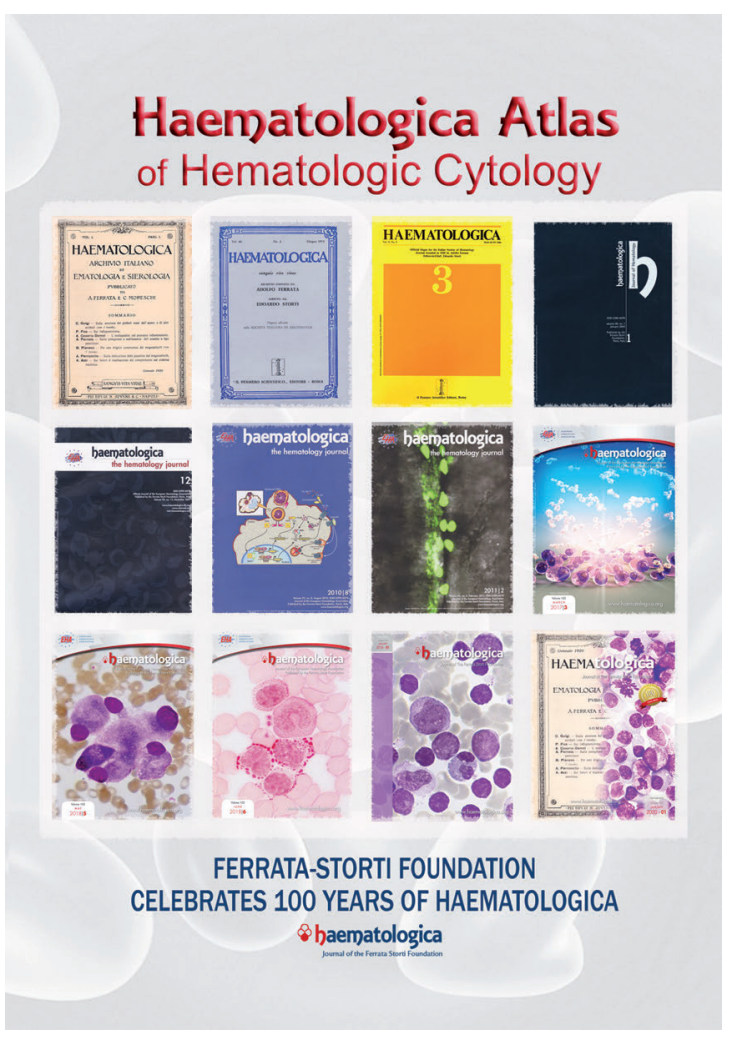

Figure 2. The Haematologica Atlas. 